\title{
Effects of Bus Stop Consolidation on Passenger Activity and Transit Operations
}

\author{
Ahmed M. El-Geneidy, James G. Strathman, Thomas J. Kimpel, \\ and David T. Crout
}

\begin{abstract}
This research addressed changes in passenger activity and operating performance after implementation of a bus stop consolidation project at TriMet, the regional transit provider for the Portland, Oregon, metropolitan area. Extensive use was made of archived bus operations and passenger activity data from TriMet's automated Bus Dispatch System. Changes in passenger activity and operating performance in route segments where stop consolidation occurred were related to changes in adjacent route segments where stops were not consolidated. The findings indicated that bus stop consolidation had no significant effects on passenger activity, whereas bus running times improved by nearly $6 \%$. Running time improvements may have been limited by insufficient schedule adjustments.
\end{abstract}

The location and spacing of bus stops is one of the most important elements of the transit service planning process. Both the budgetary resources of the transit provider and the travel times of passengers are affected by the spacing of stops. The trade-offs involved in stop spacing may appear to be straightforward (i.e., minimizing the transit provider's operating costs versus maximizing passengers' access to service), but the reality of the decision-making process is more complex. Consider the following expected consequences of increasing the distance between bus stops on a hypothetical route: $(a)$ bus running times will decline and thus reduce operating costs that can, in turn, be translated into additional vehicle miles of service for a given operating budget; $(b)$ variations in bus running time will decline and save the transit provider nonrevenue service time in the form of excess recovery and layover time as well as reducing passenger waiting times; and $(c)$ passengers' access and egress times required to travel to and from stops will increase, and their in-vehicle travel times will decrease.

Commonly, only the third item is emphasized in empirical research related to bus stop planning. The first and second items are frequently mentioned as possible benefits resulting from bus stop consolidation, but they have not been extensively tested or evaluated other than through simulations. Determination of the appropriate spacing between bus stops involves trade-offs between the convenience of passengers using a stop and the passengers already aboard a bus who are delayed each time the bus stops (1). Although

A. M. El-Geneidy, Department of Civil Engineering and Humphrey Institute of Public Affairs, University of Minnesota, 500 Pillsbury Drive SE, Minneapolis, MN 55455. J. G. Strathman and T. J. Kimpel, Center for Urban Studies, Portland State University, 506 SW Mill Street, Room 350, Portland, OR 97201. D. T. Crout, TriMet, 4012 SE 17th Avenue, M.S. HPD2, Portland, OR 97202-3940.

Transportation Research Record: Journal of the Transportation Research Board, No. 1971, Transportation Research Board of the National Academies, Washington, D.C., 2006, pp. 32-41. the effects of stop spacing on service reliability and passenger waiting times are fairly well understood (2-4), they are not generally considered in the service planning and evaluation literature (5). This is surprising given that waiting times represent the most onerous time component of the transit journey, as evidenced by estimates that the marginal value of waiting times exceeds in-vehicle times by approximately a factor of three (6).

Analyses of the interrelationships among stop spacing, service use, and operating performance have traditionally been hampered by the costs and difficulties associated with manual data collection. As such, analytical and simulation approaches have frequently been used to study stop spacing (7-10). However, with the increasing deployment of automatic vehicle location and automatic passenger counter technologies, the costs of recovering data on transit operations and passenger activity have plummeted. It is now possible to analyze empirically the effects of changes in stop spacing on operating performance and passenger activity using archived data from these systems.

This study examined changes in operating performance and passenger activity associated with a bus stop consolidation program at TriMet, the transit provider for the Portland, Oregon, metropolitan area. The objective of the program was to improve service reliability and vehicle running times by increasing the spacing between bus stops while minimizing patronage losses from reductions in stop accessibility. The analysis focused on an interlined route subject to stop consolidation. Drawing on archived data from TriMet's automated Bus Dispatching System (BDS), passenger activity and operations performance in segments of the route subject to stop consolidation were examined, and the changes that occurred after consolidation were identified. Changes on segments where consolidation occurred were compared with changes on other segments of the study route where stop consolidation did not take place. Thus, the approach had the characteristics of an experimental design.

\section{BUS STOP SPACING IN TRANSIT INDUSTRY}

Most transit providers have developed bus stop spacing standards to support service planning activity. Benn's (5) survey of the transit industry showed that $85 \%$ of respondents had adopted stop spacing standards, a substantial increase over the $62 \%$ of respondents in a 1984 survey reporting that they had done so. That stop spacing standards are increasingly common in the transit industry probably reflects the often intense conflict surrounding the location and spacing of stops. Furth and Rahbee (7) noted that stop spacing guidelines can be used to provide transit agencies with an 
objective way to resist pressure to add unnecessary stops or eliminate stops.

Although stop spacing standards are common, the standards themselves are hardly uniform (5). Even within transit agencies, stop spacing standards can cover fairly large distance ranges, providing service planners with considerable latitude but also exposing the agency to greater outside pressures. Table 1 summarizes stop spacing standards from three industry-level reports $(5,11,12)$ and from TriMet's (13) service planning guide. Generally, the distance between stops is inversely related to the density of development (which proxies demand), ranging from approximately every other intersection in central business districts to as much as $0.5 \mathrm{mi}$ in lower density surroundings. Even within a given category, the stop spacing range is fairly substantial. This is particularly evident in lower density rural settings, where standards can yield as few as two or as many as 12 stops per mile.

Furth and Rahbee (7) observed that stops in northern European cities are spaced much farther apart than those in comparable U.S. settings, yet European transit systems are still able to capture a greater share of the urban travel market. Reilly (14) also found that the common European practice was to space stops at three to four per mile as compared with the U.S. practice of seven to 10 per mile. One possible explanation for the closer spacing of stops in the United States may be related to sources of operating subsidies. In contrast with European systems, whose operating subsidies are provided from national sources, U.S. transit systems rely on state and local sources for their operating support. This distinction may contribute to the greater emphasis on maximizing service coverage and access in U.S. transit systems (15) versus a greater emphasis on maximizing operating efficiency in European systems. The relatively high density of stops in U.S. transit systems results in accessibility levels at which it is not uncommon for many transit riders to be within walking distance (usually defined as one quarter of a mile) of several stops. Thus, although elimination of stops can result in reduced accessibility for some passengers, the aggregate reduction in accessibility from stop consolidation can be relatively small. For example, Benn (5) cited a 1992 study conducted by New York's Metropolitan Transit Authority showing that after an increase in the distance between stops of more than $40 \%$, resulting accessibility declined by only $12 \%$.

\section{BUS STOP SPACING, SERVICE RELIABILITY, AND TRANSIT USE}

From the perspective of a transit provider, optimal transit service can be characterized by a limited number of stops with high and predictable passenger activity and few service reliability problems.
Passengers prefer that buses arrive promptly at stops spaced such that access, egress, and waiting times are minimized $(1,16)$. Passengers also seek to minimize their combined in-vehicle and outof-vehicle travel times, with the latter carrying a higher implicit monetary penalty (17-19). Out-of-vehicle times are influenced by stop accessibility as well as by service reliability, both of which affect passenger wait times at stops $(2,4,20,21)$. Service reliability problems also affect in-vehicle times in the form of increased bus running times $(10,22-24)$. Studies suggest, from a theoretical standpoint, that bus stop spacing, patronage, and service reliability are inherently linked.

Previous research on bus stop spacing and location has primarily been analytical in nature. The earliest work focused on simple hypothetical service environments, whereas more recent efforts have attempted to simulate conditions representing actual routes or service environments using analytical optimization models and programming methods $(7,10,23,25-27)$.

The work of Vuchic and Newell (9) represents a pioneering effort in the area of bus stop spacing. They defined the problem in terms of transit users' time minimization. Their analysis evaluated tradeoffs between access and in-vehicle times with respect to distances between stops. They demonstrated that density of stops should increase monotonically with density of demand along a route and should decrease monotonically with number of people on board. Optimal stop spacing was represented as the distance at which marginal changes in transit users' access and in-vehicle times were equalized. Given uniform population density, Vuchic and Newell then mathematically derived the optimal stop spacing for a hypothetical route. Their results demonstrated that service with larger vehicle capacities and passenger loads (e.g., commuter rail) is best designed with few stops; feeder service can be used to concentrate passenger movements.

Subsequent work on stop spacing broadened the scope of the problem to include transit operating costs. Wirasinghe and Ghoneim (10), for example, defined optimal spacing as a minimization problem with respect to passenger access, egress, and in-vehicle time cost, as well as transit operating cost and the cost of building and maintaining stops. The addition of stop-related costs and operating costs yielded greater optimal distances between stops than solutions based solely on passengers' travel time minimization. Saka (23) extended this line of research further by translating improvements in operating speed from optimal stop spacing to corresponding reductions in fleet size and capital cost savings.

More recent work on stop spacing has focused on analytical and mathematical simulations using representative time and monetary values for passengers and transit providers. Work by Van Nes and Bovy (8), for example, focused on operational conditions representative of transit systems in the Netherlands. Their estimates of

TABLE 1 Selected Bus Stop Spacing Standards

\begin{tabular}{lcccc}
\hline Service Environment & TriMet & TTI (11) & Benn (5) & TRB (12) \\
\hline High-density (80+ units/acre, CBD) & $400-600 \mathrm{ft}$. & $300-1,000 \mathrm{ft}$. & - & $650-875 \mathrm{ft}$. \\
Non-CBD & - & - & - & $-528 \mathrm{ft}$. \\
Fully developed residential (22-80 units/acre) & $500-750$ & $500-1,200$ & - \\
Low-density residential (4-22 units/acre) & $600-1,000$ & $600-2,500$ & $-660-880$ \\
Rural (less than 4 units/acre) & "As needed” & $650-2,640$ & $-2,640$ \\
\hline
\end{tabular}

NotE: All distances are in feet. TTI = Texas Transportation Institute; CBD = central business district. 
optimal stop spacing distances for a large and small city accounted for passengers' access, waiting, and in-vehicle times, as well as the transit provider's operating costs and revenues. Their simulation also explicitly considered the effects of access and service frequency on transit demand. Van Nes and Bovy derived optimal spacing distances for a variety of alternative scenarios ranging from the simple access-in-vehicle time minimization problem posed by Vuchic and Newell to a comprehensive joint cost minimization solution for the full set of passenger and operator variables. Their findings in the latter case yielded optimal stop spacing distances of $600 \mathrm{~m}$ for a small city and $800 \mathrm{~m}$ for a large city. These distances were approximately twice as great as the observed distances in selected systems in the Netherlands and other Western European cities.

Furth and Rahbee (7) employed a dynamic programming approach to determine the optimal number and location of bus stops for a heavily used route in the Massachusetts Bay Transportation Authority system. Using the route's stop-level patronage data and a geographic information system, they initially allocated boardings and alightings from each stop on the route to parcels in the route corridor. They then determined the number and location of stops in the corridor that minimized passengers' total time costs and the operating costs of the route given assumed values of walking and riding time, operating costs, and other operating factors. In contrast to the existing 37 stops, the model indicated that the optimal number of stops was 19, with several at new locations. Average spacing increased from approximately 200 to $400 \mathrm{~m}$. Passengers' average walking time increased $0.60 \mathrm{~min}$, whereas their in-vehicle times declined $1.8 \mathrm{~min}$. Average vehicle running times declined $4.3 \mathrm{~min}$ per trip. Under the optimal stop spacing solution, the combined savings to passengers and the agency was estimated as $\$ 132$ per hour.

Analytical studies of optimal bus stop spacing have provided valuable insights regarding the complex trade-offs involved in planning service. The findings from previous research, particularly more recent work closely approximating the actual operating environments of transit systems, consistently indicate that bus stops are too closely spaced in the United States and that consolidation is thus warranted. There is considerable anecdotal evidence of stop consolidation efforts under way in U.S. transit systems. These efforts may be a response to the accumulating evidence reported in the literature and may be motivated by gradually worsening traffic congestion and service reliability problems. Whatever the reason, elimination or relocation of bus stops is among the more contentious issues that transit planners are likely to encounter. Research based on analytical models provides helpful guidance and some level of justification for such activities, but actual empirical evidence linking stop spacing, service reliability, and service use is lacking.

\section{TRIMET'S BUS STOP CONSOLIDATION PROGRAM}

In 2001, TriMet operated 93 bus routes encompassing 1,460 directional miles and 8,190 stops. At the system level, the average spacing between bus stops in 2001 was approximately $940 \mathrm{ft}$. The average number of daily boardings in 2001 was nearly 180,000 , or about 22 boardings per stop.

As is the case with many urban transit providers, TriMet has faced growing challenges in its efforts to deliver reliable and timely bus service over a regional road system that has become increasingly congested. The Portland region grew rapidly during the 1990s. The region's annual population growth rate over the decade slightly exceeded $2 \%$, whereas its annual rate of growth in vehicle miles of travel (VMT) was just under 5\%. Given that roadway capacity grew at about half the rate of VMT, the region's travel time index expanded at nearly a $2 \%$ rate, and its ranking among the metropolitan areas covered in the Texas Transportation Institute's annual mobility reports fell from 25th in 1990 to 10th in $2000(28)$.

Many of the transit service delivery problems commonly associated with worsening traffic conditions, however, were substantially mitigated by TriMet's adoption of Intelligent Transportation Systems technologies in the 1990s. In 1998, the agency implemented the BDS, which included automatic vehicle location technology based on the Global Positioning System and more widespread deployment of automatic passenger counters. The BDS provided bus operators with real-time information on schedule adherence, and extensive archived operations and passenger data provided operations managers, field supervisors, service planners, schedulers, maintenance managers, and market researchers with the information they needed to adapt to changes in the operating environment. Thus, despite worsening conditions, a number of service performance and quality indicators (e.g., on-time performance, running times, headway maintenance, recovery and layover requirements) either stabilized or improved over the latter part of the decade (29). In light of these outcomes, TriMet has been recognized as an industry leader for its ability to recover data with advanced technology and to effectively translate those data into higher quality and more efficient bus service (30).

After its initial efforts focusing on the use of BDS data to improve operations, TriMet turned its attention to the more basic question of route design, including the location and spacing of bus stops. In 1999, the agency launched the Streamline project. The stated goal of the project was to "improve service reliability and reduce travel time while also improving patron safety, accessibility and comfort on select routes" (31). An objective related to this goal was to reduce operating costs while maintaining service frequency. Bus stop consolidation and relocation was just one of several elements included in the Streamline project. Other project components included signal priority, roadway improvements (e.g., bus only-queue jump-bypass lanes, curb extensions and ramps, intersection-turning changes), enhanced stop amenities, on-street parking restrictions, and changes made to ensure compliance with the Americans with Disabilities Act. Changes in routing to provide more direct service were also considered.

With respect to stop consolidation, the approach adopted by TriMet service planners in the Streamline project consisted of initially breaking down a selected route into segments. A "clean slate" approach was then followed to locate and space stops in a given corridor (i.e., route segment). The first step involved identification of the segment's "anchor" stops at transfer points, major transit trip generators, and major intersections. Once the anchor stops were located, the next step was to place additional stops between the anchor points according to the agency's stop spacing standards. Also factored into the process were stop location considerations and other circumstances, including the following:

- Generally placing stops at the far side of intersections with signal priority; 
- Selecting stop locations well connected to the pedestrian infrastructure, providing easy neighborhood access;

- Ensuring that stop locations facilitate safe street crossing;

- Preserving stops with a history of regular lift activity;

- Locating stops in a way that minimizes effects associated with traffic delay and traffic safety;

- Ensuring compatibility of stops with adjacent properties;

- Locating opposing stops in pairs;

- Ensuring that stop sites are on level slopes with adequate visibility; and

- Ensuring that stop location decisions reflect input from the public and from neighborhood and business associations.

The focus of the present analysis was Route 4-Fessenden/104Division, which provides interlined radial service to downtown Portland and was the first route subject to streamlining. Service on the reconfigured route commenced in 2000. The 4/104 was among the most heavily patronized routes in the TriMet bus system, with approximately 7,500 weekday boarding trips and more than 45 board- ing trips per vehicle hour in early 2000. It was also among the lowest performers in terms of reported excess wait time per passenger, a passenger-based service reliability measure (32). Figure 1 shows the segments of the 4/104 where stop consolidation or relocation (or both) occurred. These "treatment" segments were the focal point of the analysis described here. Another set of segments adjacent to each of the treatment segments is also shown in Figure 1. These segments served as "controls" in the analysis, reflecting exogenous changes occurring on the route over time. Thus, the analysis related changes observed in the treatment segments to those observed in the control segments.

Table 2 summarizes stop changes by direction for the 4/104. The 4-Fessenden exhibited a net reduction of four inbound and six outbound stops, whereas the 104-Division exhibited a net reduction of five inbound and seven outbound stops. In one instance (i.e., 104 outbound), the reduction simply reflected elimination of stops; in the other cases, new stops were added after consolidation or relocation of existing stops. The net reduction in stops led to an increase in average spacing between inbound stops of more
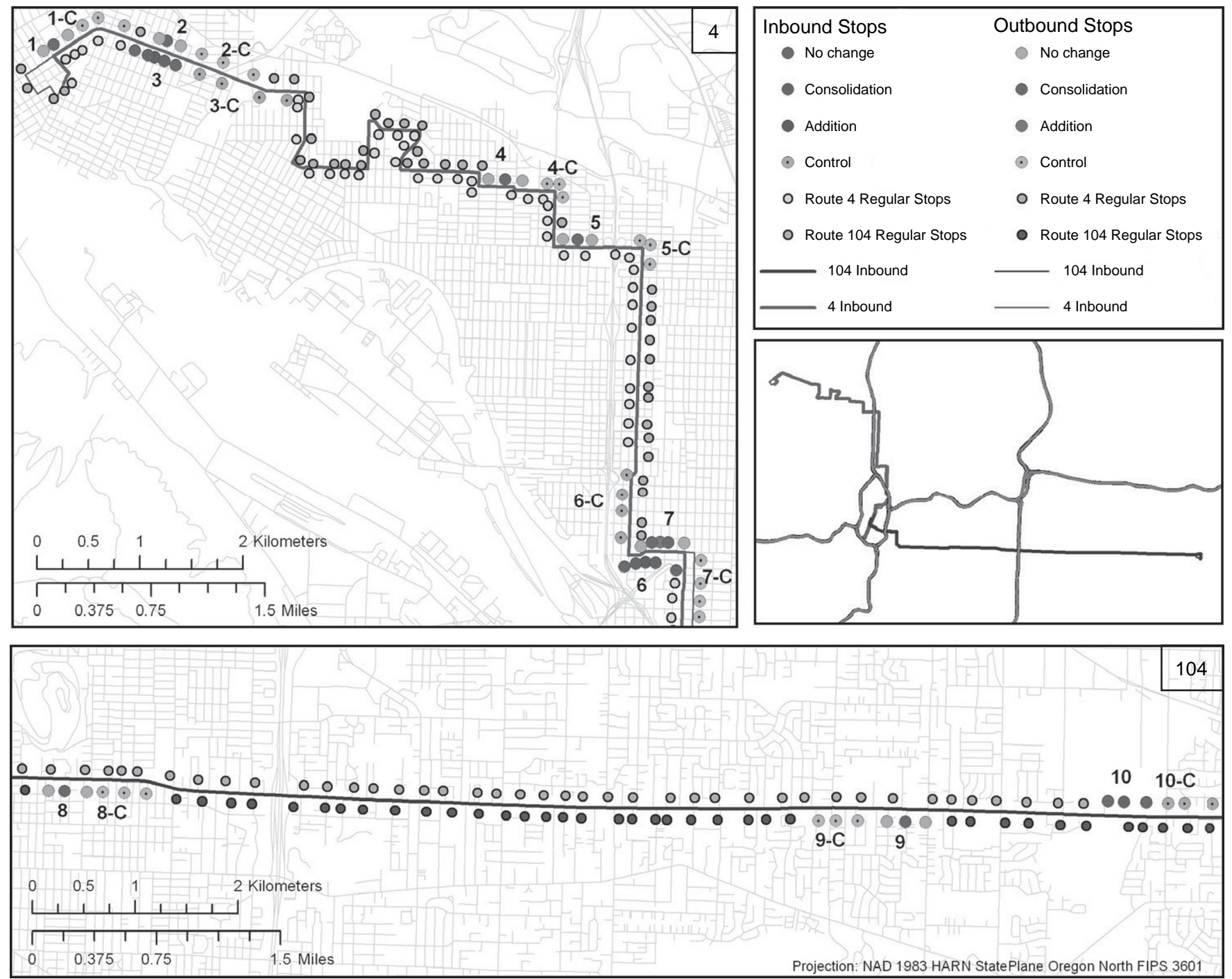

FIGURE 1 4-Fessenden/104-Division stop consolidation segments. 
TABLE 2 Summary of Stop Changes on Route 4-Fessenden/104-Division

\begin{tabular}{llcccc}
\hline Route & Direction & Stops Before/After & Stops Removed & Added & Avg. Spacing Before/After \\
\hline 4 & Inbound & $67 / 63$ & 8 & 4 & $933 / 992 \mathrm{ft}$. \\
4 & Outbound & $78 / 72$ & 8 & 2 & $820 / 890 \mathrm{ft}$. \\
104 & Inbound & $84 / 79$ & 8 & 3 & $839 / 892 \mathrm{ft}$. \\
104 & Outbound & $95 / 88$ & 7 & 0 & $742 / 801 \mathrm{ft}$. \\
\hline
\end{tabular}

than $6 \%$ and an increase of more than $8 \%$ between outbound stops.

\section{RESEARCH DESIGN}

The objective of the analysis was to examine changes in passenger activity and operating performance in the treatment segments (where stop consolidations and relocations occurred) relative to changes in the control segments (where no changes in stop locations were made). The initial step involved linking each scheduled bus trip that occurred before the change with its exact counterpart from the period after the change. This trip matching produced a paired sample, or a two-period panel, which had the advantage of reduced sampling error relative to the alternative of drawing independent samples from each period (33).

Trip segment (e.g., passenger activity per trip and segment) was the unit of analysis for the various statistical tests conducted. Each paired trip generated $n$ treatment observations and $n$ control observations, where $n$ is the number of route control and treatment segments. Each observation was calculated as the change in the value of a given variable after implementation, or

value change $=$ postimplementation value - preimplementation value

Paired-sample $t$-tests were used to determine whether there statistically significant differences in transit performance and demand between the two time periods and between control and treatment segments. The following variables were tested: boardings, alightings, the sum of boardings and alightings, running time (boardings plus alightings), the coefficient of variation (CV) of running time, and the headway $\mathrm{CV}$.

In addition to tests conducted to determine statistically significant changes, regression models were used to control for the effects of other factors that could have influenced bus performance and passenger activity. The specifications of the regressions were as follows:

boardings + alightings $=f$ (pretreatment, posttreatment, precontrol, population, income, Route-104, a.m.-inbound)

running time $=f($ pretreatment, posttreatment, precontrol, Route-104, a.m.-inbound, physical stops, unscheduled stops, boardings, alightings, lifts, schedule delay, number of signals, transit signal priority, segment length)
$\mathrm{CV}$ running time $=f$ (pretreatment, posttreatment, precontrol, $\mathrm{CV}$ actual stops, $\mathrm{CV}$ schedule delay, $\mathrm{CV}$ lifts, $\mathrm{CV}$ boardings + alightings, Route-104, a.m.-inbound, number of signals, transit signal priority, segment length)

CV headway delay $=f($ pretreatment, posttreatment, precontrol, CV actual stops, CV origin headway delay, CV lifts, CV boardings + alightings, Route-104, a.m.-inbound, number of signals, transit signal priority)

A detailed description of each variable used in the models is presented in Table 3. Three segment dummy variables in each of the regressions were used to capture changes in passenger activity, running time, running time variation, and headway variation relative to the omitted reference category, which represented the control segments after implementation of stop consolidation. The covariates in the regressions represented the most theoretically relevant variables included in empirical studies of the determinants of passenger activity, running time, and service reliability $(4,20,29,34,35)$.

For example, it was expected that passenger activity would be directly related to the size of the resident population within a quarter mile of stops and would be inversely related to the population's income level. Running time was expected to increase with the number of scheduled stops in a segment, lift activity, and passenger activity and to decrease during morning peak inbound trips relative to outbound trips in the evening peak. Schedule delay could be either positively or negatively related to running time. If delay is chronic and persistent, it is likely to have a positive effect on running time. Alternatively, if delay is circumstantial and operators exploit recovery opportunities, delay could be inversely related to running time. It was hypothesized that variations in running time and headways would be similarly related to variations in the same set of variables specified in the running time regression. A dummy variable for 104-Division was included to capture differences in passenger activity and operations relative to the 4-Fessenden. Selective introduction of transit signal priority (TSP) was also an element of TriMet's Streamline project. Because TSP can influence service performance, its effect was controlled by means of a dummy variable. Finally, a dummy variable for the number of signalized intersections was included in the models to control for variations caused by such intersections.

The analysis focused on inbound trips during the morning peak service period (7:00 to 9:00 a.m.) and outbound trips during the evening peak (4:00 to 6:00 p.m.), because these were the two operating periods driving the stop planning process (7). Three months of weekday, stop-level passenger activity, service reliability, and operational data were obtained from TriMet's BDS data archive for both the preimplementation and postimplementation time periods. These periods 
TABLE 3 Description of Variables

\begin{tabular}{|c|c|}
\hline Variable & Description \\
\hline Boardings + alightings & Average of the sum of passenger boardings and alightings per trip segment \\
\hline Running time & Average bus running time (in seconds) per trip segment \\
\hline CV running time & Coefficient of variation of bus running time (in seconds) per trip segment \\
\hline CV headway delay & Headway coefficient of variation (in seconds) per trip segment \\
\hline Pretreatment & A dummy variable equaling one if the observation occurred in a treatment segment prior to stop consolidation \\
\hline Posttreatment & A dummy variable equaling one if the observation occurred in a treatment segment after stop consolidation \\
\hline Precontrol & A dummy variable equaling one if the observation occurred in a control segment prior to stop consolidation \\
\hline Population & Population residing within 1/4 mile of segment bus stops calculated with GIS from 2000 Census block data \\
\hline Income & $\begin{array}{l}\text { Median income of households residing within } 1 / 4 \text { mile of segment bus stops, calculated with GIS from } 2000 \text { Census block } \\
\text { group data }\end{array}$ \\
\hline Boardings & Average of the sum of passenger boardings per trip segment \\
\hline Alightings & Average of the sum of passenger alightings per trip segment \\
\hline Lifts & Average number of lift operations per trip segment \\
\hline Physical stops & Number of scheduled stops per trip segment \\
\hline Unscheduled stops & Number of unscheduled per trip segment \\
\hline Schedule delay & Average delay (in seconds) at the segment origin compared to schedule \\
\hline CV boardings + alightings & The coefficient of variation of the sum of boardings and alightings per trip segment \\
\hline CV lifts & The coefficient of variation of the number of lift operations per trip segment \\
\hline CV schedule delay & The coefficient of variation of delay at the segment origin \\
\hline CV actual stops & The coefficient of variation of number of scheduled and unscheduled stops per trip segment (number of dwells) \\
\hline CV origin headway delay & The coefficient of variation of headway delay at the segment origin \\
\hline AM-inbound & A dummy variable equaling one for morning peak inbound trip segments \\
\hline Route-104 & A dummy variable equaling one if the trip segment occurs on the 104-Division \\
\hline TSP & Number of traffic signals with transit signal priority along each segment \\
\hline Number of signals & Number of traffic signals along each segment \\
\hline Segment length & Length of the studied segment (in feet) \\
\hline
\end{tabular}

corresponded to approximately 6 months before and 6 months after bus stop consolidation and relocation took place. The source data were cleaned and then aggregated to the trip segment level by summarizing over all days on a per trip basis. As a means of ensuring robustness, a 30-trip observation threshold was set for calculating averages and CVs. This process resulted in 166 total treatment trip segment observations and 166 control trip segment observations. Table 4 includes summary statistics for all of the variables included in the study.

\section{RESULTS}

\section{Composite Evaluation}

The results of the preimplementation-postimplementation differences in means tests for the treatment and control trip segments are presented in Table 5. Results for the three passenger activity variables and the three operating performance variables are reported. None of the passenger activity variables (boardings, alightings, or boardings plus alightings) were found to change significantly for the treatment segments with the exception of boardings along control segments. Average boardings per trip segment increased by approximately $10 \%$ after implementation of the stop consolidation program. Although a decrease in boardings along control segments occurred during the two time periods, the change was not statistically significant. However, a statistically significant difference was observed when changes in boardings in the treatment segments were compared with changes in the control segments, indicating a net increase in boardings.

The most notable change that can be observed from the data in Table 5 was the reduction in running time after implementation of stop consolidation. Bus running time on treatment segments declined by slightly more than $9 \mathrm{~s}$ (or 9.6\%). Bus running time also declined by more than $3.5 \mathrm{~s}$ (or $2.9 \%$ ) on the control segments. The difference between the reductions in the treatment and control segments (5.41 s) represented a net $5.7 \%$ reduction in running time attributable to stop consolidation. Neither the run time variability variable nor the headway delay variability variable proved to be significant; this indicates that stop consolidation had no appreciable effect on service reliability.

Taken together, the results of the $t$-tests focusing on the passenger activity and running time variables indicate that stop consolidation achieved the intended objective of concentrating passenger movements among fewer stops, thus reducing time lost from deceleration, dwell, and acceleration. Most important, the savings in running time did not come at the expense of a loss in passengers.

\section{Disaggregated Evaluation}

\section{Demand Model}

The results of the passenger activity and operations regressions are presented in Table 6 . Regarding the total passenger activity equation 
TABLE 4 Summary Statistics

\begin{tabular}{lrrrr}
\hline Variable & Minimum & Maximum & \multicolumn{1}{c}{ Mean } & Std. Deviation \\
\hline Boardings + alightings & 0.00 & 15.97 & 4.07 & 3.04 \\
Running time & 27.68 & 190.63 & 100.94 & 41.07 \\
CV running time & 0.13 & 1.97 & 0.30 & 0.15 \\
CV headway delay & -126.98 & 230.06 & 1.11 & 21.75 \\
Pretreatment & 0.00 & 1.00 & 0.25 & 0.43 \\
Posttreatment & 0.00 & 1.00 & 0.25 & 0.43 \\
Precontrol & 0.00 & 1.00 & 0.25 & 0.43 \\
Population & 203.08 & $2,555.73$ & $1,455.66$ & 467.32 \\
Income & $21,199.14$ & $47,639.80$ & $34,582.92$ & $6,555.47$ \\
Boardings & 0.00 & 10.35 & 1.92 & 2.28 \\
Alightings & 0.00 & 6.39 & 2.16 & 1.49 \\
Lifts & 0.00 & 0.33 & 0.01 & 0.03 \\
Physical stops & 2.00 & 4.00 & 3.08 & 0.64 \\
Unscheduled stops & 0.00 & 1.33 & 0.38 & 0.33 \\
Schedule delay & -61.55 & 776.51 & 254.33 & 194.85 \\
CV boardings + alightings & 0.00 & 6.16 & 0.88 & 0.74 \\
CV lifts & 0.00 & 7.87 & 1.07 & 2.20 \\
CV schedule delay & -25.11 & 852.37 & 4.25 & 47.50 \\
CV actual stops & 0.00 & 6.16 & 0.66 & 0.72 \\
CV origin headway delay & -548.19 & 216.91 & -0.95 & 35.33 \\
AM-inbound & 0.00 & 1.00 & 0.28 & 0.45 \\
Route-104 & 0.00 & 1.00 & 0.24 & 0.43 \\
TSP & 0.00 & 1.00 & 0.25 & 0.44 \\
Number of signals & 0.00 & 1.00 & 0.45 & 0.50 \\
Segment length & 785.10 & $3,180.37$ & $1,515.61$ & 568.63 \\
\hline & & & & \\
& & & & \\
& & & &
\end{tabular}

(boardings plus alightings), none of the treatment or control tripsegment dummy variable coefficients were statistically significant. Thus, all changes observed in passenger movements were attributable to changes in the size and income of the population residing within a quarter mile of stops on route segments after stop consolidation. In this case, passenger activity was estimated to increase with the size of the accessible population and decrease with growth in the median income of that population. Given the considerable overlap of the quarter-mile stop buffers along these segments, however, elimination of stops had only a limited effect on reducing the size of the

TABLE 5 Treatment and Control Trip Segment Paired-Sample Means Differences

\begin{tabular}{lccc}
\hline Variable & Treatment & Control & Treatment - Control \\
\hline Avg. boardings & -0.02 & $0.21^{* *}$ & $-0.23^{*}$ \\
Avg. alightings & 0.03 & -0.01 & 0.046 \\
Avg. boardings + & 0.01 & 0.20 & -0.19 \\
$\quad$ alightings & & & $-4.30^{*}$ \\
Avg. running time & $-8.12^{* *}$ & $-3.81^{* *}$ & -0.025 \\
CV running time & -0.02 & 0.003 & -1.24 \\
CV headway delay & 0.42 & 1.67 & \\
\hline
\end{tabular}

*Indicates statistical significance at the $90 \%$ level.

**Indicates statistical significance at the $95 \%$ level. accessible population. The route dummy variable was statistically significant, with the 104-Division estimated to serve about two fewer passengers per trip segment than the 4-Fessenden. Morning peak inbound service was not found to be appreciably different from evening peak outbound service in terms of passenger activity.

\section{Running Time Model}

In the running time regression, both the preimplementation and postimplementation treatment dummy coefficients were significant. The estimated effects represented the change in running time due to changes in impedance. Treatment segment running time was found to increase by $22 \mathrm{~s}$, whereas control segment running time was found to increase by $0.4 \mathrm{~s}$. Given that the treatment and control segments were adjacent to each other, it is probably erroneous to interpret this difference as being due to traffic-related factors, with a more likely interpretation being that it was schedule related.

Although scheduled running times were reduced in conjunction with elimination of stops on the 4/104, it appears that they were not reduced sufficiently on the treatment segments. It should be noted that nominal running times on the treatment segments did decline, but this decline was due to a reduction in the number of stops per trip made on these segments (which averaged 3.6 stops preimplementation and 2.6 stops postimplementation). Given that the regression indicated that a one-stop reduction leads to a decline in running time of $29 \mathrm{~s}$, this indicates that about three fourths ( 22 of 29 s) of 
TABLE 6 Regression Results

\begin{tabular}{|c|c|c|c|c|}
\hline & Boardings + Alightings & Running Time & CV Running Time & CV Headway \\
\hline Intercept & $\begin{array}{c}5.53 \\
(4.95)\end{array}$ & $\begin{array}{c}-43.74 \\
(-5.52)\end{array}$ & $\begin{array}{c}0.31 \\
(7.55)\end{array}$ & $\begin{array}{l}-2.39 \\
(-0.64)\end{array}$ \\
\hline Pretreatment & $\begin{array}{c}-0.48 \\
(-1.06)\end{array}$ & $\begin{array}{c}-5.98 \\
(-2.59)\end{array}$ & $\begin{array}{c}0.05 \\
(1.91)\end{array}$ & $\begin{array}{c}2.20 \\
(0.61)\end{array}$ \\
\hline Posttreatment & $\begin{array}{l}-0.42 \\
(-0.92)\end{array}$ & $\begin{array}{l}16.06 \\
(5.29)\end{array}$ & $\begin{array}{c}0.01 \\
(0.19)\end{array}$ & $\begin{array}{c}2.79 \\
(0.83)\end{array}$ \\
\hline Precontrol & $\begin{array}{l}-0.20 \\
(-0.47)\end{array}$ & $\begin{array}{c}-0.43 \\
(-0.18)\end{array}$ & $\begin{array}{c}0.01 \\
(0.58)\end{array}$ & $\begin{array}{c}-0.11 \\
(-0.03)\end{array}$ \\
\hline Population & $\begin{array}{c}0.01 \\
(2.55)\end{array}$ & & & \\
\hline Income & $\begin{array}{l}-0.01 \\
(-2.60)\end{array}$ & & & \\
\hline Boardings & & $\begin{array}{c}6.66 \\
(14.37)\end{array}$ & & \\
\hline Alightings & & $\begin{array}{c}6.32 \\
(8.96)\end{array}$ & & \\
\hline Lifts & & $\begin{array}{c}37.39 \\
(1.83)\end{array}$ & & \\
\hline Physical stops & & $\begin{array}{c}29.15 \\
(10.33)\end{array}$ & & \\
\hline Unscheduled stops & & $\begin{array}{c}1.82 \\
(0.57)\end{array}$ & & \\
\hline Schedule delay & & $\begin{array}{c}0.01 \\
(0.04)\end{array}$ & & \\
\hline CV boardings + alightings & & & $\begin{array}{c}0.34 \\
(7.69)\end{array}$ & $\begin{array}{c}-12.13 \\
(-1.83)\end{array}$ \\
\hline CV lifts & & & $\begin{array}{c}0.01 \\
(1.49)\end{array}$ & $\begin{array}{c}0.27 \\
(0.51)\end{array}$ \\
\hline CV schedule delay & & & $\begin{array}{c}0.01 \\
(0.18)\end{array}$ & \\
\hline CV actual stops & & & $\begin{array}{l}-0.32 \\
(-7.02)\end{array}$ & $\begin{array}{l}18.04 \\
(2.64)\end{array}$ \\
\hline $\mathrm{CV}$ origin headway delay & & & & $\begin{array}{c}0.24 \\
(7.80)\end{array}$ \\
\hline AM-inbound & $\begin{array}{l}-0.38 \\
(-1.02)\end{array}$ & $\begin{array}{c}-10.87 \\
(-3.77)\end{array}$ & $\begin{array}{l}-0.01 \\
(-0.45)\end{array}$ & $\begin{array}{l}-2.22 \\
(-0.84)\end{array}$ \\
\hline Route-104 & $\begin{array}{l}-1.84 \\
(-4.16)\end{array}$ & $\begin{array}{c}-15.70 \\
(-7.13)\end{array}$ & $\begin{array}{c}-0.02 \\
(-1.01)\end{array}$ & $\begin{array}{l}-0.18 \\
(-0.06)\end{array}$ \\
\hline TSP & & $\begin{array}{c}-12.12 \\
(-5.19)\end{array}$ & $\begin{array}{c}-0.02 \\
(-0.63)\end{array}$ & $\begin{array}{c}0.62 \\
(0.15)\end{array}$ \\
\hline Number of signals & & $\begin{array}{c}29.93 \\
(14.17)\end{array}$ & $\begin{array}{c}0.03 \\
(1.10)\end{array}$ & $\begin{array}{c}3.33 \\
(0.97)\end{array}$ \\
\hline Segment length & & $\begin{array}{c}0.01 \\
(5.63)\end{array}$ & $\begin{array}{c}0.01 \\
(-3.52)\end{array}$ & \\
\hline$R^{2}$ & 0.198 & 0.926 & 0.259 & 0.208 \\
\hline$N$ & 332 & 332 & 332 & 332 \\
\hline
\end{tabular}

Note: $t$-statistics are reported in parentheses.

the potential time savings was not realized. This interpretation is reinforced by the fact that, in TriMet's bus fleet, each vehicle's status in relation to the schedule is continuously reported on a control head located next to the operator, thus permitting relatively continuous adjustments to schedule adherence. TriMet did not implement an aggressive schedule readjustment after implementation of bus stop consolidation; accordingly, drivers had more time to do the runs, and the effects of consolidation tended to be minor.
Determining the "true or real" effect of bus stop consolidation on run times requires interpretation of both the treatment (pretreatment and posttreatment) and physical stops variables. Combining these variables yielded a total decline in mean running time along consolidation segments of $7.11 \mathrm{~s}$ per trip and segment. Various models were tested with different specifications and sample sizes to increase the confidence level of this 7.11-s savings. Similar levels of savings were found (approximately $7.3 \mathrm{~s}$ and $8.0 \mathrm{~s}$ ). 
Running times were also estimated to be about $11 \mathrm{~s}$ shorter per trip segment during the morning peak period than during the evening peak, consistent with previous findings (29). The effects of passenger movements on running time were estimated to be just over $6.5 \mathrm{~s}$ per boarding and just over $6 \mathrm{~s}$ per alighting, with lift operations adding about $37 \mathrm{~s}$; however, the latter variable did not prove significant. TSP was found to have a statistically significant, negative effect on running time; that is, TSP was estimated to result in a decrease in run time of approximately $12 \mathrm{~s}$ per trip and segment. Finally, both segment length and number of traffic signals in the segment were found to have statistically significant positive effects on running time.

\section{Variation Models}

Neither of the regressions related to the two service reliability variables preformed well. Running time variation per trip segment was estimated to increase with increases in variations of passenger movements. None of the estimated coefficients of the headway delay variations measured in the trip destination equation were significant with the exception of the variance in the number of stops made and headway delay variation measured at the trip origin. This is surprising given that variance in passenger activity was expected to have an effect on headway delay variation measured at the trip destination. Further research is recommended in this area.

\section{CONCLUSIONS}

This empirical analysis focused on the effects of bus stop consolidation on passenger activity and bus operating performance. The analysis made extensive use of archived automatic vehicle location and automatic passenger counter data recorded at the bus stop level. Passenger activity was found to be unaffected by stop consolidation, whereas bus running times improved. The regression findings suggest that further running time savings could be realized with proper scheduling adjustments. From the perspective of passengers, the results indicate that the reductions in accessibility from stop consolidation were offset by time improvements in the line haul portion of their trips. Thus, the utility of their trip making appears to have been unaffected by stop consolidation, whereas the transit provider gained from improvements in efficiency.

Savings in running time at the route level were not quantified in the analysis as a result of other changes that occurred along the route during the same time period. Accordingly, improvements in reliability due to consolidation were difficult to isolate except at the trip-segment level of analysis. A more aggressive implementation of bus stop consolidation policy could lead to greater improvements in service productivity, yet this strategy should be approached with caution in that it may ultimately lead to a loss in ridership. Yet, strategic decisions are needed in such situations to measure savings in trip time and compare these savings with the expected loss in passenger demand. Finally, although service reliability improvements are a commonly expected consequence of stop consolidation, we found no evidence of changes in running time variation or headway variation in the route segments studied.

The main contribution of this work resides in its empirical orientation. Although there has been a considerable amount of research on the subject of stop location and spacing, previous work has relied heavily on analytical or simulation methods rather than empirical analyses of actual operational data. Generally, the present results lend support to claims from previous analytical and simulation studies that stops are too closely spaced and that bus stop spacing service standards should be relaxed. The findings are also consistent with the expected consequences of increasing traffic congestion, which degrades travelers' line haul times but does not affect their access or egress times.

\section{ACKNOWLEDGMENTS}

The authors express their appreciation to Kenneth Dueker, Anthony Rufolo, and Robert Bertini of Portland State University for their contributions to the analysis.

\section{REFERENCES}

1. Kittelson and Associates, Inc. Transit Capacity and Quality of Service Manual. U.S. Department of Transportation, Washington, D.C., 2003.

2. Bowman, L., and M. Turnquist. Service Frequency, Schedule Reliability and Passenger Wait Times at Transit Stops. Transportation Research Part A, Vol. 15, No. 6, 1981, pp. 465-471.

3. Sterman, B., and M. Schofer. Factors Affecting Reliability of Urban Bus Services. Transportation Engineering Journal, Vol. 102, No. 1, 1976, pp. 147-159.

4. Turnquist, M. A Model for Investigating the Effect of Service Frequency and Reliability on Bus Passenger Waiting Times. In Transportation Research Record 663, TRB, National Research Council, Washington, D.C., 1978, pp. 70-73.

5. Benn, H. Bus Route Evaluation Standards. Transportation Research Board, Washington, D.C., 1995.

6. Mohring, H., J. Schroeter, and P. Wiboonchutikula. The Value of Waiting Time, Travel Time, and a Seat on a Bus. Rand Journal of Economics, Vol. 18, No. 1, 1987, pp. 40-56.

7. Furth, P. G., and A. B. Rahbee. Optimal Bus Stop Spacing Through Dynamic Programming and Geographic Modeling. In Transportation Research Record: Journal of the Transportation Research Board, No. 1731, TRB, National Research Council, Washington, D.C., 2000, pp. 15-22.

8. van Nes, R., and P. H. L. Bovy. Importance of Objectives in Urban Transit-Network Design. In Transportation Research Record: Journal of the Transportation Research Board, No. 1735, TRB, National Research Council, Washington, D.C., 2000, pp. 25-34.

9. Vuchic, V., and G. Newell. Rapid Transit Interstation Spacings for Minimum Travel Time. Transportation Science, Vol. 2, No. 2, 1968, pp. 303-339.

10. Wirasinghe, S. C., and N. S. Ghoneim. Spacing of Bus Stops for Many to Many Travel Demand. Transportation Science, Vol. 15, No. 3, 1981, pp. 210-221.

11. TCRP Report 19: Guidelines for the Location and Design of Bus Stops. TRB, National Research Council, Washington, D.C., 1996.

12. NCHRP Synthesis of Highway Practice 69: Bus Route and Schedule Guidelines. TRB, National Research Council, Washington, D.C., 1980

13. Tri-Met Service Standards. Tri-County Metropolitan District of Oregon, Portland, Ore., 1989.

14. Reilly, J. M. Transit Service Design and Operation Practices in Western European Countries. In Transportation Research Record: 1604, TRB, National Research Council, Washington, D.C., 1997, pp. 3-8.

15. Sale, J., and B. Green. Operation Costs and Performance of American Public Transit Systems. Journal of the American Planning Association, Vol. 45, No. 1, 1979, pp. 22-27.

16. Murray, A. Strategic Analysis of Public Transport Coverage. SocioEconomic Planning Sciences, Vol. 35, No. 3, 2001, pp. 175-188.

17. Kemp, M. A. Some Evidence of Transit Demand Elasticities. Transportation, Vol. 2, No. 1, 1973, pp. 25-51.

18. Pushkarev, B. S., and J. M. Zupan. Public Transportation and Land Use Policy. Indiana University Press, Bloomington, Ind., 1977.

19. Lago, A. M., and P. D. Mayworm. Transit Service Elasticities. Journal of Transport Economics and Policy, Vol. 15, No. 2, 1981, pp. 99-119. 
20. Abkowitz, M., and J. Tozzi. Research Contributing to Managing Transit Service Reliability. Journal of Advanced Transportation, Vol. 21 No. 1, 1987, pp. 47-65.

21. Turnquist, M. Strategies for Improving Reliability of Bus Transit Service. In Transportation Research Record 818, TRB, National Research Council, Washington, D.C., 1981, pp. 7-13.

22. Levinson, H. S. Analyzing Transit Travel Time Performance. In Transportation Research Record 915, TRB, National Research Council, Washington, D.C., 1983, pp. 1-6.

23. Saka, A. A. Model for Determining Optimum Bus-Stop Spacing in Urban Areas. Journal of Transportation Engineering, Vol. 127, No. 3, 2001, pp. 195-199.

24. Koffman, J. Automatic Passenger Counting Data: Better Schedules Improve On-Time Performance. In Fifth International Workshop on Computer-Aided Scheduling of Public Transport, Springer-Verlag, Montreal, Quebec, Canada, 1990

25. Chien, S. I., Z. Qin, and R. Liu. Optimal Bus Stop Locations for Improving Transit Accessibility. Presented at 82nd Annual Meeting of the Transportation Research Board, Washington, D.C., 2003.

26. Kuah, G. K., and J. Perl. Optimization of Feeder Bus Routes and Bus Stop Spacing. Journal of Transportation Engineering, Vol. 114, No. 3, 1988, pp. 341-354.

27. Murray, A., and X. Wu. Accessibility Tradeoffs in Public Transit Planning. Journal of Geographical Systems, Vol. 5, No. 1, 2003, pp. 93-107.
28. Schrank, D., and T. Lomax. The 2003 Annual Urban Mobility Report. Texas Transportation Institute, Texas A\&M University System, College Station, Tex., 2003.

29. Strathman, J., K. Dueker, T. Kimpel, R. Gerhart, K. Turner, P. Taylor, S. Callas, and D. Griffen. Service Reliability Impacts of Computer-Aided Dispatching and Automatic Location Technology: A Tri-Met Case Study. Transportation Quarterly, Vol. 54, No. 3, 2000, pp. 85-102.

30. Furth, P. G., B. J. Hemily, T. H. J. Muller, and J. G. Strathman. TCRP Web Document 23: Uses of Archived AVL-APC Data to Improve Transit Performance and Management: Review and Potential. Transportation Research Board, Washington, D.C., 2003.

31. Bus Stop Guidelines 2002. Tri-County Metropolitan District of Oregon, Portland, Ore., 2002.

32. Route Performance Report. Tri-County Metropolitan District of Oregon, Portland, Ore., 2000.

33. Wonnacott, T., and R. Wonnacott. Introductory Statistics for Business and Economics. John Wiley and Sons, New York, 1972.

34. Levinson, H. S., and O. Brown-West. Estimating Bus Ridership. In Transportation Research Record 994, TRB, National Research Council, Washington, D.C., 1984, pp. 8-12.

35. Strathman, J., T. Kimpel, K. Deuker, R. Gerhart, and S. Callas. Evaluation of Transit Operations: Data Applications of Tri-Met's Automated Bus Dispatching System. Transportation, Vol. 29, No. 3, 2002, pp. 321-345.

The Bus Transit Systems Committee sponsored publication of this paper. 